strated by the Hawaii and Tottori groups in hamsters, rabbits and mice - success in humans may not be far away.

The first Japanese clinic to offer the procedure is the Hiroshima Assisted Reproductive Technology (HART) Clinic, also in western Japan. Sofikitis admits to a "very small number" of preliminary trials that have already taken place in the country but this is the first time the method has been made available to the public. About 30 couples who have approached Sofikitis have been referred to Katsuhiko Takahashi at the HART Clinic and trials are due to begin in late March or early April, depending on the availability of suitable patients.

Following Japan's belated approval of gene therapy, this appears to be another example of its conservative medical establishment being slow to embrace a new, experimental procedure. The ethical problems associated with IVF are far fewer than for gene therapy, and the method is being pioneered by a Japanese group, making the technology easily available. Takahashi points out that Japan has few centres with the expertise necessary to carry out human microinsemination.

Results from this year's trials in the United States already show improved fertilization rates. In August, Sofikitis will be going to Cornell University in New York to participate in trials there. With steady progress being made, he hopes that it is only a matter of time before his department and its collaborators will be able to announce the world's first ROSNI baby.

TIMO HANNAY Tokyo

\title{
Tailored therapy can lower costly Gaucher treatments
}

A panel of experts, convened by the US National Institutes of Health (NIH) last month, recommends carefully managed dosing of replacement enzymes as a way of reducing the high cost of treating patients with Gaucher disease - a rare inherited disorder that affects between 10,000 and 20,000 people in the United States.

The high cost of treatment for Gaucher disease, which can run to as much as $\$ 400,000$ per year per patient, is often singled out by legislators as an example of why there should be government-mandated price controls for drugs. The likelihood of such legislation being passed, however, with the present Republican-led Congress, is remote.

Although the highest preva- Panel chair, Edward lence of Gaucher McCabe.

\section{disease is among}

Ashkenazi Jews, it affects most ethnic populations, albeit with considerable variability. Because of a genetic defect, a critical cerebrosidase enzyme is missing or in short supply. Without it, glucocerebroside can accumulate to excess levels causing severe damage to certain tissues in affected individuals. Before enzyme replacement therapy was available, treatment of Gaucher disease typically entailed total or partial splenectomy, frequent transfusions, hip replacements, and bone marrow transplants.
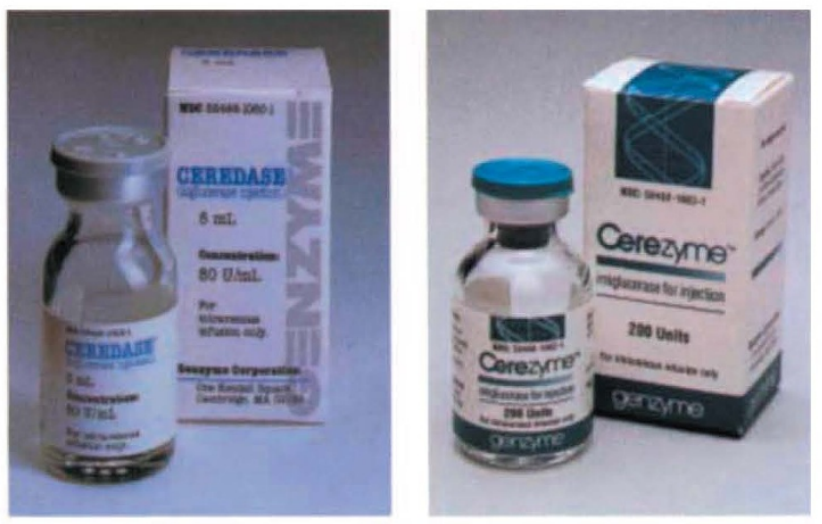

Ceredase, and its recombinant alternative, Cerezyme - both produced by Genzyme for the treatment of Gaucher disease are often singled out because of the high cost of treatment. An NIH panel says 'tailored' therapy may help lower costs.

Enzyme replacement therapy first became available in 1991 when Ceredase, which is derived from human placental tissues and produced by Genzyme Corporation of Cambridge, Massachusetts, was approved by the US Food and Drug Administration (FDA). In mid-1994, FDA approved a recombinant alternative to Ceredase, Cerezyme, which is also produced by Genzyme.

Although the panel notes that the annual cost per patient of enzyme replacement therapy can be as high as $\$ 400,000$, the figures can vary widely, depending on the severity of the disease and the dosage requirements of each patient. Consequently, the average annual cost is more like $\$ 145,000$ per patient, according to a Genzyme spokesperson.

In its deliberations, the panel tried to walk a fine line in balancing the needs of the patient against the cost of therapy. "Because response to therapy is varied and unpredictable, each patient's progress must be monitored closely, but we know a sizeable number do well on lower dose regimens," says panel chair, Edward R. B. McCabe, professor and executive chair of paediatrics at the University of California, Los Angeles School of Medicine.

The panel urged wider discussion of drug pricing issues, particularly where rare, so-called orphan diseases, like Gaucher disease, may lead to similar dilemmas. "The panel was concerned that companies dealing with even more rare disorders might be reluctant to get into the field," McCabe says. Adds panelist William Sly, chairman of biochemistry and molecular biology at Washington University School of Medicine, St Louis, Missouri, "The community at large tried in vain to get other companies to tackle Gaucher disease. So now it is grateful to Genzyme for taking that risk, and the treatment results are very favourable. Now people are critical not because of the science but because of the economics."

JEFFREY L. FOX Washington, DC 